\title{
Fungal endophytic communities associated to the phyllosphere of grapevine cultivars under different types of management
}

\author{
Carla Marisa Reis VARANDA ${ }^{a, *}$, Mônica OLIVEIRA ${ }^{a}$, Patrick MATERATSKI $^{b}$, \\ Miguel LANDUM ${ }^{a}$, Maria Ivone Esteves CLARA ${ }^{c}$, Maria do Rosário FÉLIX ${ }^{c}$ \\ ${ }^{a}$ ICAAM - Instituto de Ciências Agrárias e Ambientais Mediterrânicas, Instituto de Investigação e Formação \\ Avançada, Universidade de Évora, Núcleo da Mitra, Ap. 94, 7006-554 Évora, Portugal \\ ${ }^{\mathrm{b}}$ MARE - Centro de Ciências do Mar e do Ambiente, Universidade de Évora, Escola de Ciências e Tecnologia, c/o \\ NemaLab, Apartado 94, 7002-554 Évora, Portugal \\ 'Departamento de Fitotecnia, Instituto de Ciências Agrárias e Ambientais Mediterrânicas, Instituto de Investigação e \\ Formação Avançada, Universidade de Évora, Núcleo da Mitra, Ap. 94, 7006-554 Évora, Portugal
}

\section{A R T I C L E I N F O}

Article history:

Received 23 March 2016

Received in revised form

26 July 2016

Accepted 1 August 2016

Available online 11 August 2016

Corresponding Editor:

Ursula Peintner

\section{Keywords:}

Biological control

Conventional mode

Endophytes

Vineyards

\begin{abstract}
A B S T R A C T
Fungal endophytes present in different asymptomatic grapevine plants (Vitis vinifera L.) located in different vineyards within Alentejo, a highly important viticulture region in Portugal, were identified in this study. Sampled grapevine plants included the three most representative cultivars in the region, Syrah, Cabernet Sauvignon, and Aragonez, growing under two different modes of management, conventional and biological. Sixteen fungal taxa were identified through sequencing of the internal transcribed spacer region. Total number of endophytic fungi isolated showed significant differences both in management mode and in cultivars, with higher numbers in grapevines under conventional mode and from Syrah cultivar. The composition of fungal endophytic communities did not show significant differences among cultivars, but differences were observed between fungal communities isolated from grapevines under biological or conventional modes. The most fungal taxa isolated from grapevines cultivated under biological mode were Alternaria alternata, Cladosporium sp., and Nigrospora oryzae, and under conventional mode Botrytis cinerea, Epicoccum nigrum, and Epicoccum sp. These differences suggest that the different products used in grapevine production have impacts in fungal endophytic composition. Further investigation of the identified fungi with respect to their antagonistic characteristics and potential use in plant protection to ensure food safety is now in course.
\end{abstract}

๑ 2016 British Mycological Society. Published by Elsevier Ltd. All rights reserved.

\section{Introduction}

Endophytes are microorganisms that live entirely within plant tissues, roots, stems, and/or leaves, without causing any apparent symptoms of disease (Petrini 1991). Fungal endophytes are ubiquitous, they have been found within all plants from the diverse habitats examined to date (Kumaresan \& Suryanarayanan 2001; Schulz et al. 2002; Rodriguez et al.

\footnotetext{
* Corresponding author. Tel.: +351 266760851; fax: +351 266760822.

E-mail address: carlavaranda@uevora.pt (C. M. R. Varanda).

http://dx.doi.org/10.1016/j.funbio.2016.08.002
}

1878-6146/@ 2016 British Mycological Society. Published by Elsevier Ltd. All rights reserved. 
2009; Pancher et al. 2012). The endophytic community in a single plant is usually composed by numerous and systematically diverse species of fungi (Petrini 1991; Oono et al. 2015). Their number and species composition is influenced by factors such as the environment (Saona et al. 2010; Yousaf et al. 2010; Núnez-Trujillo et al. 2012), plant physiology (Islam et al. 2010), anthropogenic factors (Rasche et al. 2006), and pathogen infections (Araujo et al. 2002; Bulgari et al. 2011; Buyer et al. 2011).

Endophytes have been gaining attention in the past decade in areas such as medicine, agriculture, and industry, mostly due to the vast potential uses of their chemically diverse secondary metabolites (Tao et al. 2008; Rodriguez et al. 2009) and their roles within plants (Oono et al. 2015). Several studies have shown that some fungal endophytes have beneficial effects on their hosts. They may act as plant growth promoters; confer tolerance to environmental stresses and pathogen and herbivore attacks, the latter for instance by decreasing the palatability of the host tissue to herbivores through the production of toxic compounds (Arnold et al. 2003; Miller et al. 2008; Bae et al. 2009; Oono et al. 2015). The role of endophytes in pathogen defence is attained through different mechanisms, namely the induction of systemic resistance, through the accumulation of pathogenesis-related (PR) proteins, expression of plant defence genes; the production of secondary metabolites that inhibit fungal growth and the competition with pathogens for the same ecological niches in terms of nutrients and space (Arnold et al. 2003; Gonzalez \& Tello 2011). On the other hand, endophytic fungi benefit from protection and nutrition from their hosts, and in some cases, reproducing sexually on dead tissues of their host plant (Saikkonen et al. 1998). This balance however may not be guaranteed in a continuous manner, either due to a decrease in plant defence or an increase in fungal virulence since some endophytes may go from a mutualistic to a parasitic lifestyle, depending on factors such as the environment, fungal community composition, host health and host-endophyte genotype-genotype interaction to name a few (Redman et al. 2001). This means that some pathogenic fungi may live as endophytes during part of their life, which is an interesting challenge for plant pathology to find out and understand what are the key differences for both endophytic and pathogenic lifestyles. This is particularly important in grapevine, where the agents known to cause some of the most important trunk diseases (excoriose, Petri disease, esca) have been isolated from inside plant tissues from both symptomatic and asymptomatic plants (Mostert et al. 2000; Halleen et al. 2007; Gonzalez \& Tello 2011; Núnez-Trujillo et al. 2012).

DNA-based approaches have been largely used in grapevine mostly to identify plant pathogenic fungi (Schmidt et al. 2003; Oliveri et al. 2007; Sánchez-Torres et al. 2008). Endophytic fungal communities have been studied less, but have showed some very interesting and important results (Martini et al. 2009; Gonzalez \& Tello 2011). Their presence has shown to interfere in wine quality through the production of toxic metabolites that some fungi produce, such as ochratoxin A (OTA) produced by Aspergillus spp. and Penicillium spp. (Cabanes et al. 2010). In addition, the accumulation of PR proteins as a result of the activation of plant defence pathways by endophytes has shown to affect wine stability (Ferreira et al.
2004). Some fungal endophytes in grapevine have, however, shown some beneficial effects such as antagonistic properties against some important pathogens. Fungi belonging to the genus Alternaria and Epicoccum have shown antagonism against Plasmopara viticola and Botrytis cinerea (Musetti et al. 2007; Polizzotto et al. 2009). These studies show that the study of endophytic communities in grapevine is essential both to shape future pest management and to produce high quality products. To our knowledge, in Portugal, data on such communities are inexistent.

The aim of this study was 1) to characterise the composition of fungal endophytic communities in grapevine plants in a region of relevant impact in grapevine production; 2) to find out if the composition of fungal communities is related to the type of management performed (biological and conventional); and 3) to find out if the composition of the fungal communities is related to the cultivar (Syrah, Cabernet Sauvignon, and Aragonez). Sampling was performed in two proximate locations in the south of Portugal (Estremoz and Évora).

Exploring endophytic diversity in different contexts will help to understand the variables responsible for structuring fungal diversity. It will also help to understand the role/influence that the communities have on the host, for example on grapevine terroir and wine characteristics, as well as to help to understand their relation with other pathogens or diseases.

\section{Materials and methods}

\section{Study sites and sample collection}

The sampling areas are located in Alentejo (south of Portugal), a major vine producing area, where the altitude ranges from 150 to $400 \mathrm{~m}$ above sea level, the climate is Mediterranean, mean temperature is $15^{\circ} \mathrm{C}$, annual rainfall is $600 \mathrm{~mm}$ and soils are mostly of schist and calcareous origin. Surveys were carried out during the period of 2014-2015.

A total of 12 vineyards in an area of $450.000 \mathrm{~m}^{2}$ were sampled representing two types of management, biological or conventional, and three most produced cultivars, Syrah, Cabernet Sauvignon, and Aragonez (synonym Tempranillo) (Table 1).

The fungicide substances used in the conventional plots were fosetyl-aluminium, folpet, cymoxanil, spiroxamine, cyflufenamid, difenoconazole, copper oxychloride, chinoxifen, and myclobutanil. These substances were used to prevent excoriose, black rot, downy and powdery mildews, and Botrytis. At the time of the survey no signs of disease were observed. The fungicide substances used in the biological plots were copper hydroxide, sulphur and extracts from Equisetum arvense and Saponaria officinalis.

Ten asymptomatic plants were randomly selected in each vineyard, totalling 120 samples. Three leaves were cut from each plant and transported to the laboratory in a refrigerated basket, stored at $4{ }^{\circ} \mathrm{C}$ and processed within the next $48 \mathrm{~h}$.

\section{Isolation of endophytic fungi}

Leaves were surface disinfected to suppress epiphytic microorganisms and cut into $0.5 \mathrm{~cm}^{2}$ sections. Disinfection consisted in a succession of $3 \mathrm{~min}$ immersions, conducted 
Table 1 - Provenience of grape leaf samples used in this study.

\begin{tabular}{llll} 
Type of management & Location & \multicolumn{1}{c}{ Cultivar } & Sample \\
\hline Biological & Estremoz & Syrah & BioEstSyr \\
& & Cabernet Sauvignon & BioEstCab \\
& & Aragonez & ConvEstSyr \\
Conventional & & Syrah & ConvEstCab \\
& & Cabernet Sauvignon & ConvEstAra \\
Biological & Évora & Aragonez & BioEvoSyr \\
& & Syrah & BioEvoCab \\
& & Cabernet Sauvignon & BioEvoAra \\
Conventional & & Aragonez & ConvEvoSyr \\
& & Syrah & ConvEvoCab \\
& & Cabernet Sauvignon & ConvEvoAra \\
\hline
\end{tabular}

under a sterile laminar airflow chamber, in a series of $96 \%$ ethanol, $3 \%$ sodium hypochlorite solution, $70 \%$ ethanol, and ultra-pure water. After disinfection, leaf pieces were dried in sterile Whatman paper, placed on Petri dishes of $9 \mathrm{~cm}$ diameter (four pieces per plate) containing Potato Dextrose Agar medium (PDA, Merck, Germany) and incubated, in darkness, for $1-2$ weeks at $23-25^{\circ} \mathrm{C}$.

Four days later, all morphologically different colonies were isolated by transferring an about $5 \mathrm{~mm}^{2}$ agar disk of the growing fungi to fresh medium (PDA). Mycelium from isolated colonies was ground in liquid nitrogen and stored at $-80^{\circ} \mathrm{C}$ for later use in DNA extraction.

\section{Fungal DNA extraction}

DNA was extracted using the CTAB (hexadecyltrimethylammonium bromide) method described by Doyle \& Doyle (1987) with some modifications. Briefly, fungal DNA powder was placed in $1.5 \mathrm{~mL}$ microtones containing pre warmed $600 \mu \mathrm{L}$ $2 \%$ CTAB extraction buffer $(20 \mathrm{mM}$ EDTA, $0.1 \mathrm{M}$ Tris- $\mathrm{HCl} \mathrm{pH}$ 8.0, 1.4 M NaCl, 2 \% CTAB, plus $4 \%$ PVP, and $0.1 \% \beta$-mercaptoethanol added just before use) and $0.5 \%$ Proteinase $\mathrm{K}$. The solution was incubated at $55{ }^{\circ} \mathrm{C}$ for $60 \mathrm{~min}$, gently mixing by inversion every $15 \mathrm{~min} ; 600 \mu \mathrm{L}$ of chloroform-isoamyl alcohol (24:1) was added to the tubes and gently mixed for $10 \mathrm{~min}$. Samples were centrifuged for $10 \mathrm{~min}$ at $5000 \mathrm{~g}$, the supernatant was then transferred to a fresh tube following the addition of 2.5 volumes of cold ethanol $\left(-20^{\circ} \mathrm{C}\right)$. Samples were gently mixed by inversion and centrifuged at $10000 \mathrm{~g}$ for $20 \mathrm{~min}$. The liquid solution was released and the DNA pellet washed with $500 \mu \mathrm{L}$ of $70 \%$ ethanol to eliminate salt residues adhered to the DNA and dried in a speed vacuum for $10 \mathrm{~min}$ at $55^{\circ} \mathrm{C}$. Pellet was resuspended in $50 \mu \mathrm{L}$ of ultrapure water and stored at $-20^{\circ} \mathrm{C}$. DNA concentration was determined using a NanoDrop ND-1.000 spectrophotometer.

\section{Fungal DNA identification}

The internal transcribed spacer (ITS) region of nuclear rDNA was amplified through PCR from genomic DNA, or lysed fungal material, by using ITS1 and ITS4 primers (White et al. 1990). PCR reactions consisted of 30-80 ng of genomic DNA, $10 \mathrm{mM}$ Tris- $\mathrm{HCl}$ ( $\mathrm{pH}$ 8.6), $50 \mathrm{mM} \mathrm{KCl}, 1.5 \mathrm{mM} \mathrm{MgCl}, 0.2 \mathrm{mM}$
dNTPs (Fermentas), $1 \mu \mathrm{M}$ of each primer, and $2.5 \mathrm{U}$ of DreamTaq DNA polymerase (Fermentas) in a total reaction volume of $50 \mu \mathrm{L}$. Amplification was carried out in a Thermal Cycler (BioRad) at $95^{\circ} \mathrm{C}$ for $2 \mathrm{~min}$ followed by 40 cycles of $95^{\circ} \mathrm{C}$ for $30 \mathrm{~s}$, $50{ }^{\circ} \mathrm{C}$ for $50 \mathrm{~s}$, and $72{ }^{\circ} \mathrm{C}$ for $60 \mathrm{~s}$ and a final extension at $72^{\circ} \mathrm{C}$ for $10 \mathrm{~min}$. Amplified products were analysed by agarose gel electrophoresis. PCR products were purified using DNA Clean \& Concentrator (Zymo Research) and sequenced in forward and reverse directions by Macrogen (The Netherlands). Sequence analysis of the ITS sequences was carried out using BioEdit Sequence Alignment Editor v.7.2.3 (Hall 1999). The search for homologous sequences was done using Basic Local Alignment Search Tools (BLAST) at the National Center for Biotechnology Information (NCBI). Sequences were identified to the species level whenever possible. All fungal sequences considered were at least $98 \%$ identical to the best hit in the NCBI database.

\section{Fungal diversity and multivariate data analysis}

To estimate if the number of operational taxonomical units (OTUs) obtained represented quality sampling efforts, a species accumulation curve was performed using EstimateS software (Colwell 2013) with the protocol of randomize individuals without replacement, using the classic formula for Chao 1 and Chao 2 and Sobs (Mao Tau) algorithm. Singletons and doubletons were also determined. Several nonparametric estimators were used to infer species richness: Bootstrap, Jack 1 and Jack 2, Chao 1 and Chao 2, ACE and ICE estimators.

Diversity of endophytes was obtained for each management mode and cultivar by calculation of Simpson diversity $\left(D=1 / \operatorname{sum}\left(P i^{2}\right)\right)$, Shannon-Wiener diversity $(H=-\operatorname{sum}(P i \cdot \ln$ $[P i]))$, and Simpson evenness indexes $(E=H / \ln [S]$, being $P i$ the number of a species divided by the total number of organisms observed and $S$ the species richness.

Multivariate analyses were performed to detect significant differences in the total number of fungi present under two different types of management 'Biological' and 'Conventional' in the three cultivars, 'Syrah', 'Cabernet Sauvignon', and 'Aragonez'. The statistical analyses of the data were performed using the PRIMER v6 software package (Clarke \& Warwick 2001) with the PERMANOVA add-on package (Anderson et al. 2008). 
Total number of fungi was calculated using the dataset from two different types of management 'Biological' and 'Conventional' and each cultivar 'Syrah', 'Cabernet Sauvignon', and 'Aragonez'. A two-way permutational analysis of variance (PERMANOVA) was applied to test the hypothesis that significant differences existed in total number of fungi between ' $\mathrm{Bi}$ ological' and 'Conventional', among 'Syrah', 'Cabernet Sauvignon', and 'Aragonez'. The PERMANOVA analysis was carried out following the two factor design: 'Management': 'Biological' and 'Conventional' (2 levels, fixed) and 'Cultivars': 'Syrah', 'Cabernet Sauvignon' and 'Aragonez' (3 levels, random). Total fungi data were square root transformed in order to scale down the importance of highly abundant fungi genera and therefore increase the importance of the less abundant ones in analysis of similarity between communities. The PERMANOVA analysis was conducted on a Bray-Curtis similarity matrix (Clarke \& Green 1988). The null hypothesis was rejected at a significance level $<0.05$ (if the number of permutations was lower than 150, the Monte Carlo permutation $p$ was used).

A Principal Component Analysis (PCA) of presence and absence of fungal species was performed to explore patterns in multidimensional data by reducing the number of dimensions with minimal loss of information. The PCA ordination was based on each of the two different types of management 'Biological' and 'Conventional' and on each of the three cultivars 'Syrah', 'Cabernet Sauvignon', and 'Aragonez'. Prior to the calculation of the PCA ordination data were $\log (\mathrm{X}+1)$ transformed.

\section{Results}

\section{Isolation and identification of endophytic fungi}

In the 2-year survey presented in this work, 120 field samples were analysed and 240 endophytic fungal isolates were obtained from two vine-producing areas. Fungal isolates were obtained in all tested plants. All isolated fungi were successfully identified based on ITS sequence analysis. Fungi were identified at species level in $40 \%$ of the isolates. The size of the generated PCR products ranged from 500 to $700 \mathrm{bp}$.

\section{Species diversity of endophytic fungi}

The 240 isolates were identified as belonging to 16 OTUs (Fig 1) representing ten fungal genera. The species accumulation curve (Fig 2), calculated using Mao Tau algorithm, which gives confidence intervals of $95 \%$, indicated that the sampling efforts made were suitable to recover most of species diversity present in the phyllospheres of the plants surveyed. The actual species number was estimated to be 17 using Bootstrap estimators, 19 using Jack 1, 20 using Chao 1, 21 using ACE, ICE, Chao 2, and 22 using Jack 2, meaning that the 16 OTUs found in this study represent more than $73 \%$ of the species richness actually present.

Nearly all isolates obtained belonged to the ascomycetes (99.6\%), only one isolate belonged to basidiomycetes (Class Agaricomycetes, Order Atheliales) (0.4\%). Within the ascomycetes, the 15 OTU represented four classes (Dothideomycetes, Leotiomycetes, Sordariomycetes, and Eurotiomycetes) being the Dothideomycetes the most representative $(60 \%)$ and the others distributed equally, with two species each. Within the Dothideomycetes, the Pleosporales were the most frequent, with seven OTUs, representing $78 \%$ of the total Dothideomycetes, $44 \%$ of the total OTUs and $66 \%$ of the total isolates found.

The number of OTUs obtained from individual plants ranged from one to five and in plots from four to ten.

Most of the OTUs obtained in this study showed to be very frequent, ten (62\%) appeared in four or more plants (plurals), two (13\%) in two plants (doubletons), and four (25\%) only in one plant (singletons).

From the 240 isolates, 159 ( $66 \%$ ) belonged either to Alternaria (89 isolates) or Epicoccum genera (70 isolates). Alternaria sp. and Epicoccum sp. were the only OTUs detected in all vineyards. Alternaria solani, Athelia sp., Diplodia seriata, Penicillium brevicompactum, and Penicillium sp. were only detected in one

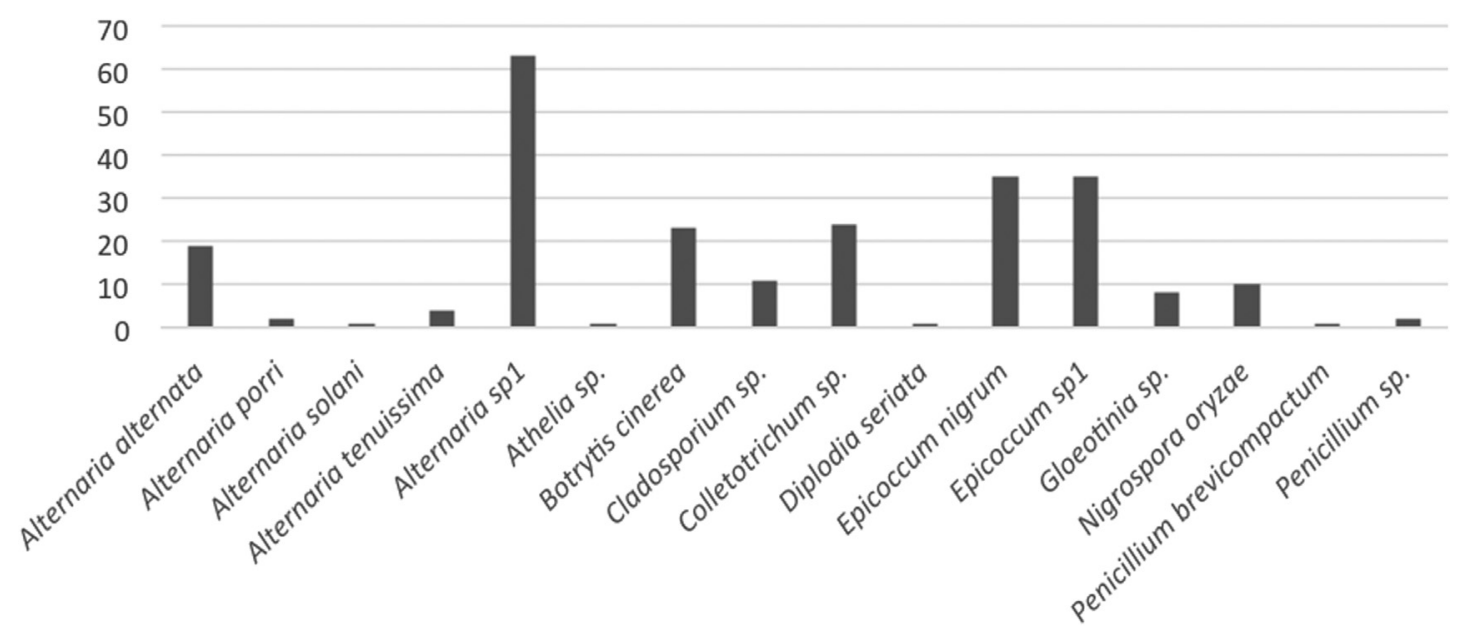

Fig 1 - Total number of fungal isolates isolated from 12 vineyards distributed by OTU. 


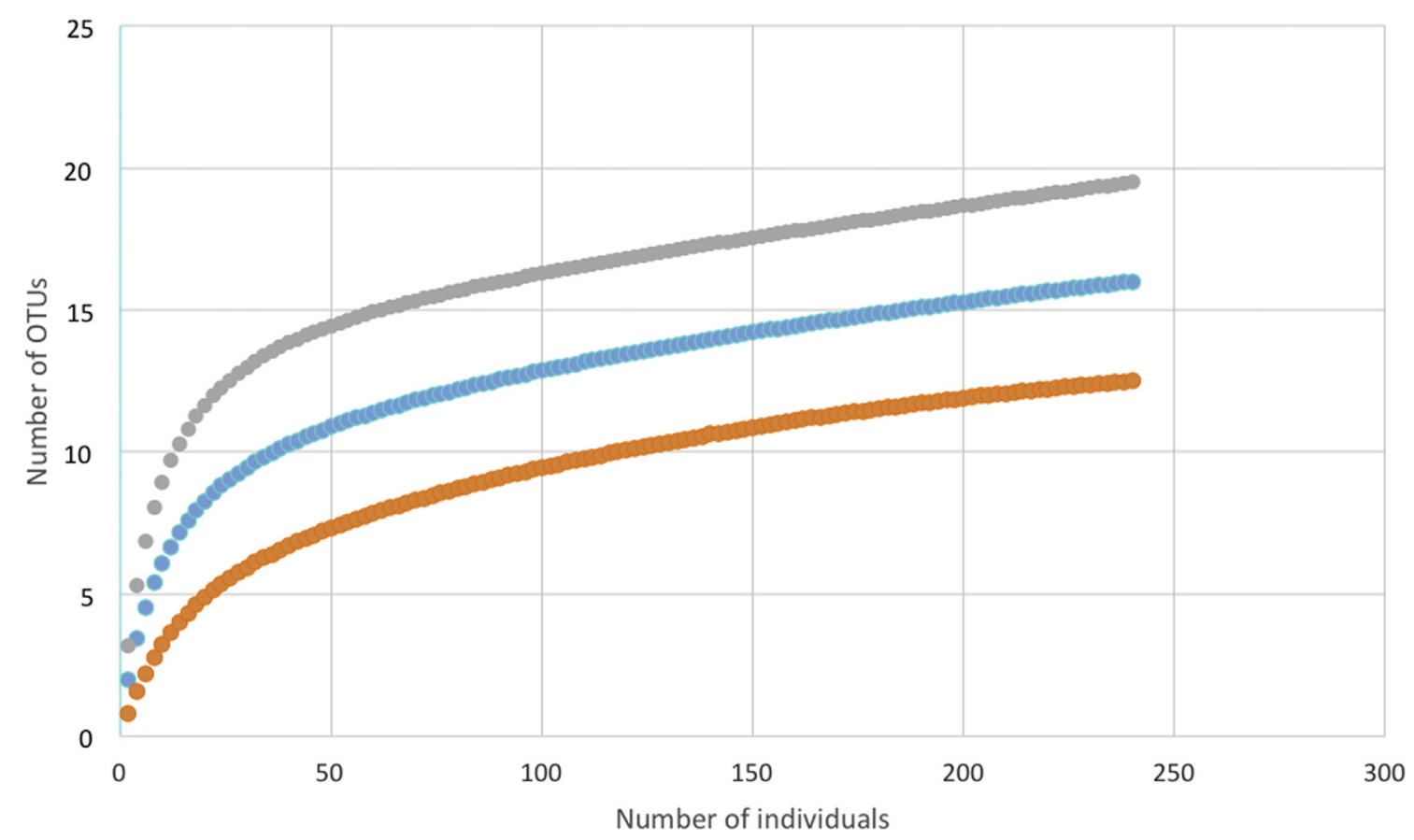

Fig 2 - Species accumulation curve showing the relation between the number of individuals (plants sampled) tested and the total number of taxa obtained. Middle line: number of fungal taxa calculated by the Mao Tau algorithm. Upper and lower lines: $95 \%$ confidence limits of the estimate of taxa number. The curve is based on 100 randomizations.

vineyard, all of them under conventional treatment, with the exception of Athelia sp., suggesting a higher diversity of fungal endophytes species in conventional vineyards.

From the 16 fungal OTU identified, four were detected solely in conventional vineyards (Alternaria porri, A. solani, Penicillium sp., and P. brevicompactum), two only in biological vineyards (Athelia sp. and D. seriata) and ten in both modes (Fig 3A).

Most common isolates (over $60 \%$ ) in conventional vineyards belonged to A. porri, A. solani, Botrytis cinerea, Epicoccum nigrum, Epicoccum sp., P. brevicompactum, and Penicillium sp.; and in biological vineyards, they belonged to Alternaria alternata, Athelia sp., Cladosporium sp., D. seriata, and Nigrospora oryzae. Alternaria tenuissima, Alternaria sp., Colletotrichum sp., and Gloetinia sp. isolates were equally common in conventional and biological vineyards.

From the 16 fungal OTU identified, 15 were detected in Syrah cultivars, 11 in Cabernet Sauvignon and nine in Aragonez. Five OTUs were detected only in Syrah cultivars (A. solani, A. tenuissima, Athelia sp., D. seriata and Penicillium sp.), one was detected only in Cabernet Sauvignon (P. brevicompactum) and none was solely detected in Aragonez cultivar. Nine OTUs were detected in all three cultivars and A. porri was detected in Syrah and Cabernet cultivars (Fig 3B).

As for the total number of isolates, $39 \%$ were detected in cv. Syrah vines, $33 \%$ in cv. Cabernet Sauvignon and $28 \%$ in cV. Aragonez. OTUs that most contributed to cv. Syrah values were A. solani, A. tenuissima, Athelia sp., B. cinerea, Colletotrichum sp., D. seriata, Epicoccum sp., N. oryzae, and Penicillium sp. Alternaria sp., E. nigrum, Gloetinia sp., and P. brevicompactum were dominant in cv. Cabernet Sauvignon vines. A. alternata was the only OTU with more isolates detected in Aragonez than in any other cultivar.
Number and distribution of the isolates of the different OTU was similar in the two localities sampled (data not shown).

The Simpson and Shannon diversity indexes indicate that fungal diversity and evenness did not vary significantly between grapevines under different management modes. As for the cultivars, Syrah presented the highest diversity index values (Table 2).

\section{Multivariate data analysis}

The total number of fungi detected was significantly $(p<0.02)$ higher on the conventional than on the biological management (mean number of fungi $\pm \mathrm{SE}$ of $2.17 \pm 0.12$ versus $1.83 \pm 0.10$ ). This was verified for the three cultivars. In biological management, the mean number of fungi \pm SE was $2.10 \pm 0.19$ in cultivar Syrah, $1.85 \pm 0.19$ in Cabernet Sauvignon and $1.55 \pm 0.16$ in Aragonez. In conventional management, the mean number of fungi \pm SE was $2.55 \pm 0.23$ in cultivar Syrah, $2.05 \pm 0.21$ in Cabernet Sauvignon and $1.90 \pm 0.20$ in Aragonez (Fig 4).

The PCA ordination of the fungal species showed that the first two components (PC1, $19.8 \%$ and PC2, $17.6 \%$ ) accounted for $37.4 \%$ of the variability of the data. PCA ordination separated samples collected under the conventional mode from the samples from the biological management, Epicoccum nigrum, Epicoccum sp., and Botrytis cinerea were shown to be more dominant in conventional mode and showed a marked separation from Alternaria alternata, Colletotrichum sp., Nigrospora oryzae, and Cladosporium sp. that are dominant in biological type of management (Fig 5).

PERMANOVA analysis revealed significant differences in the factor 'Cultivar' $(p<0.0105)$. In biological management, 


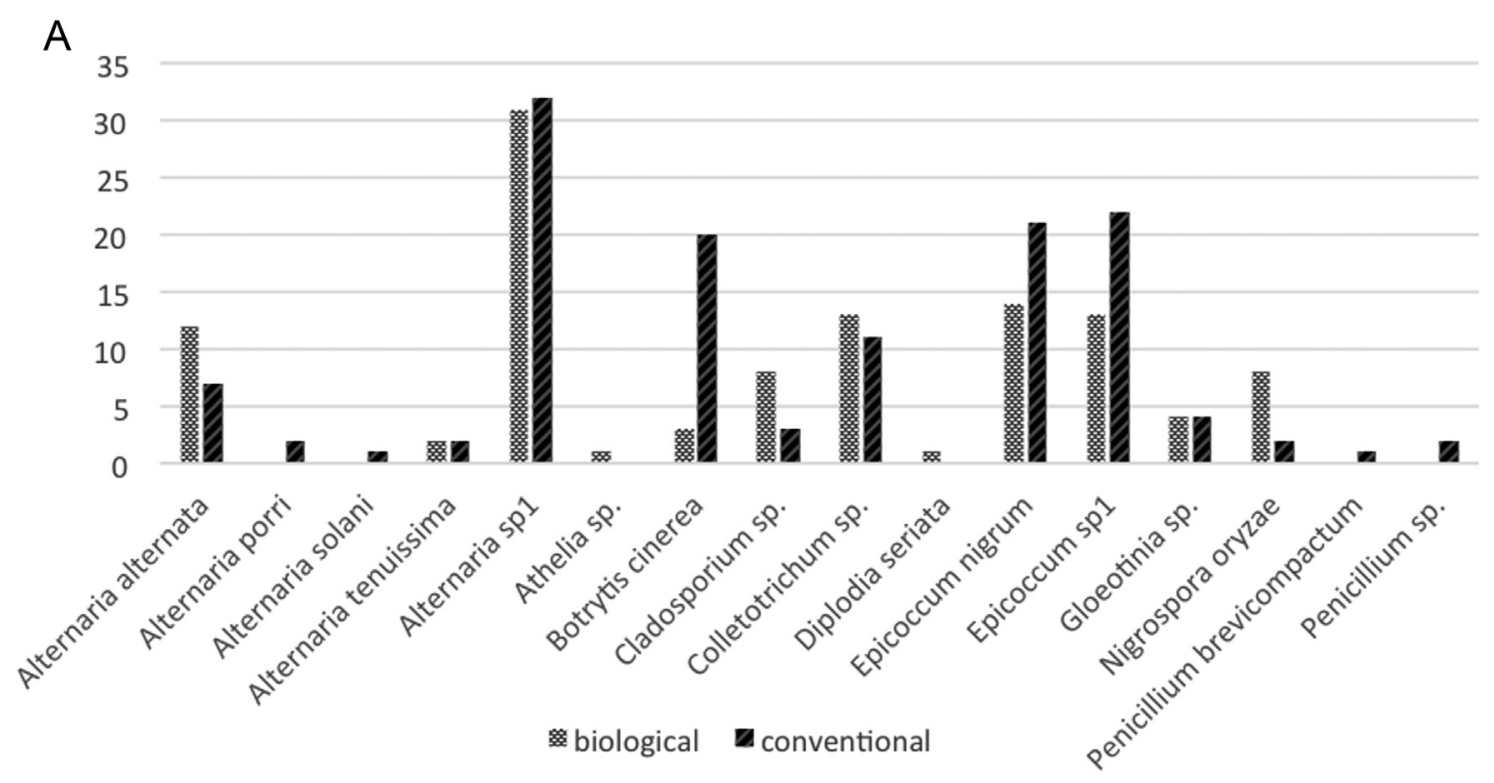

B

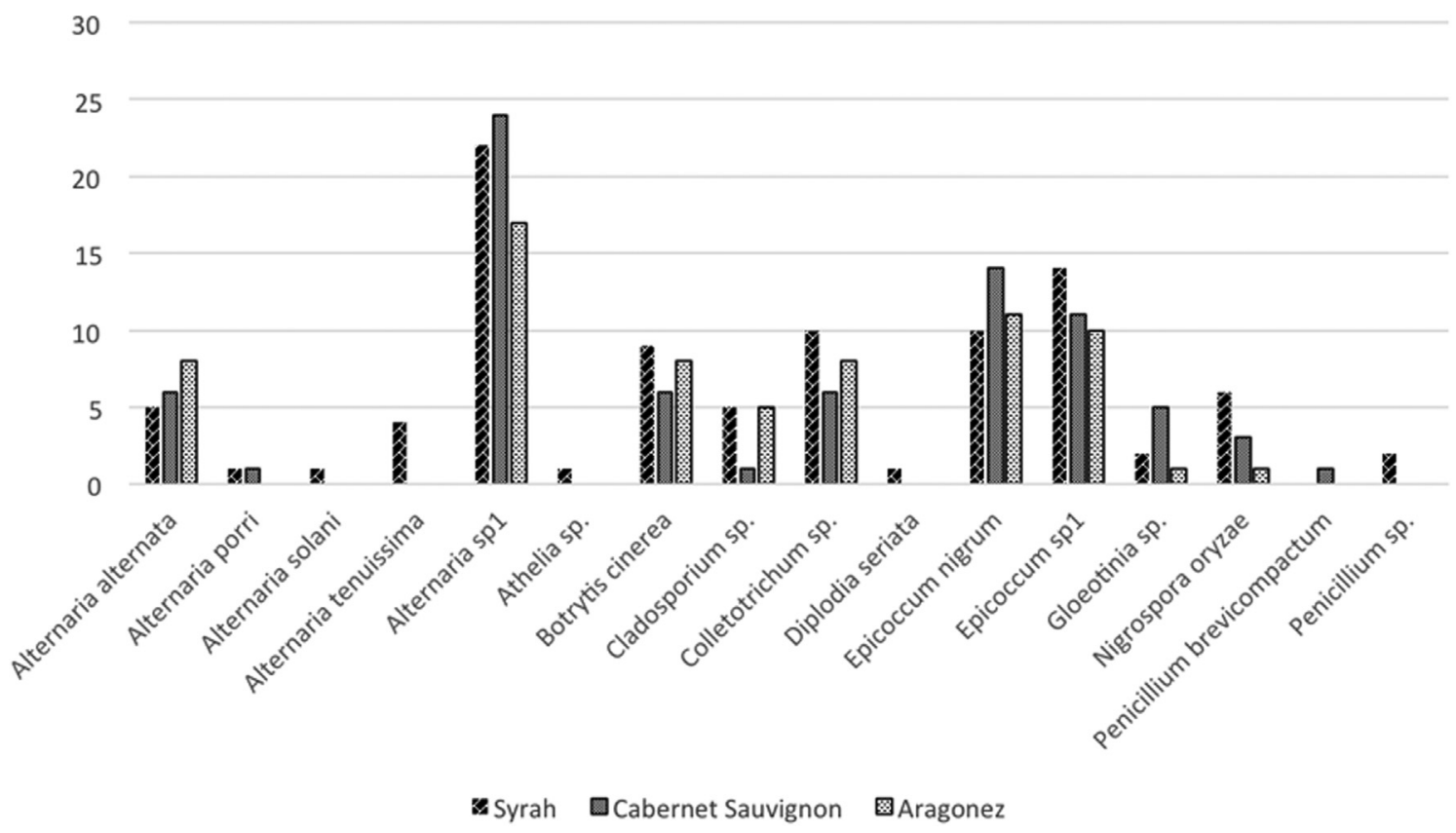

Fig 3 - Number of fungal isolates per OTU identified in the vineyards under study according to type of management (A) and cultivar (B).

Table 2 - Species richness, diversity, and evenness of phyllosphere endophytic fungi from grape obtained in this study.

\begin{tabular}{llcccc} 
& & Species richness & Simpson diversity & Shannon diversity & Evenness \\
\hline \multirow{2}{*}{ Mode } & Conventional & 14 & 6,6 & 2,12 & 0,8 \\
& Biological & 12 & 6,73 & 2,124 & 0,85 \\
& Aragonez & 9 & 6,53 & 1,98 & 0,9 \\
& Cabernet & 11 & 5,86 & 1,89 & 0,79 \\
& Syrah & 15 & 8,05 & 2,32 & 0,86 \\
\hline
\end{tabular}




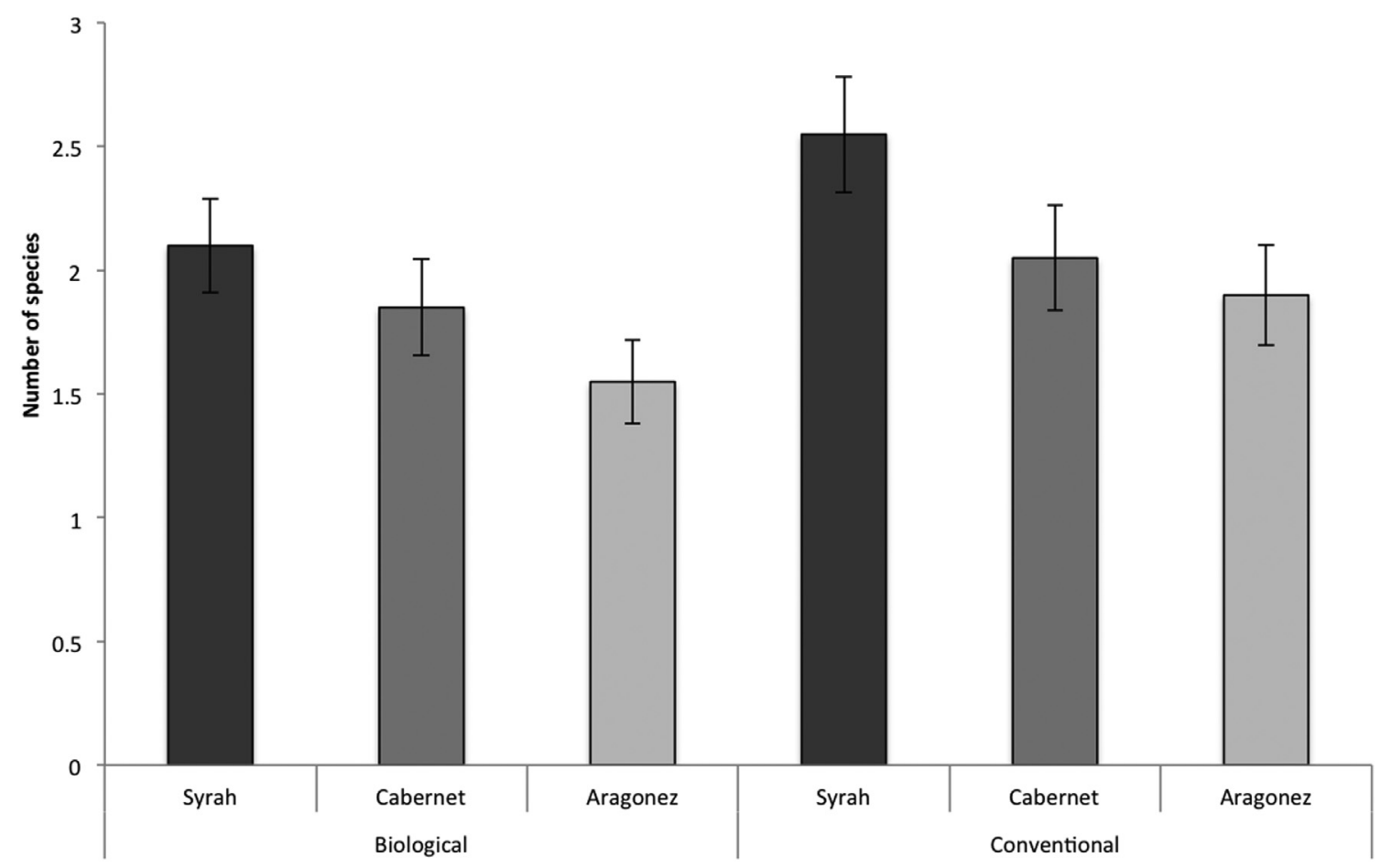

Fig 4 - Mean number of endophytic fungal OTUs \pm standard error (SE) present in the phyllosphere of each cultivar (Syrah, Cabernet Sauvignon and Aragonez) under two different types of management (biological and conventional).

individual pairwise comparisons detected a significantly higher number of fungi on the Syrah cultivar than Aragonez cultivar (Pairwise Tests, $p_{\text {syrah versus aragonez }}<0.0399$ ), however, no significant differences were revealed between Syrah and Cabernet (Pairwise Tests, $p_{\text {syrah versus cabernet }}<0.3587$ ), or between Cabernet and Aragonez (Pairwise Tests, $p_{\text {aragonez versus }}$ cabernet $<0.2367)$. In conventional management, individual pairwise comparisons also detected a significantly higher number of fungi on the Syrah cultivar than Aragonez cultivar (Pairwise Tests, $p_{\text {syrah versus aragonez }}<0.0395$ ), and no significant differences between Syrah and Cabernet (Pairwise Tests, $p_{\text {syrah }}$ versus cabernet $<0.1249$ ), or between Cabernet and Aragonez (Pairwise Tests, $\left.p_{\text {aragonez versus cabernet }}<0.5955\right)$. In general, the number of fungi was significant consistently higher on Syrah cultivar than Aragonez and Cabernet cultivars (Pairwise Tests, $p_{\text {syrah versus aragonez }}<0.0032, p_{\text {syrah versus cabernet }}<0.082$, $p_{\text {aragonez ver- }}$ sus aragonez $<0.2194)$.

The PCA ordination of the fungal species in the factor 'Cultivar' showed that the first two components (PC1, 19.8\% and PC2, $17.6 \%$ ) accounted for $37.4 \%$ of the variability of the data. PCA ordination did not separate samples according to the cultivar (Fig 6).

\section{Discussion}

This study describes the composition of endophytic fungal communities within the plant phyllosphere of three cultivars of grapevine from Alentejo, under different modes of management. Endophytes were isolated in fall, at the end of the vegetative cycle, before yellowing and falling of leaves. Leaves present the highest frequency and diversity of fungal endophytes (Gonzalez \& Tello 2011) due to the less barriers fungi face for infection when compared to other parts of the plant (Arnold \& Lutzoni 2007) or to the successful colonization of above-ground fungal endophytes that travel among hosts as spores.

In this study, the cumulative curves for species richness approached asymptotic growth (Fig 2), suggesting that most fungal species were detected and sample was representative. Similar accumulation curves were obtained for each cultivar and each management mode analysed individually (data not shown). The species abundance of fungal endophytes in grapevine was mostly comprised of frequent taxa (75 \%) rather than rare species (singletons), meaning that there is a large proportion of species that were repeatedly isolated and that showed to be characteristic in grapevine, regardless of the mode of management or cultivar. This result is in agreement with other studies performed in grapevine adult trees (Casieri et al. 2009; Gonzalez \& Tello 2011; Pancher et al. 2012) and may be due to the fact that some endophyte OTUs become specialized on plant tissues and occupy a specific ecological role in the plant. The stable and strong colonization of these fungi may then prevent the colonization of new different species.

We achieved ITS PCR amplification for all 240 fungal isolates obtained and sequence analyses placed them into 16 different OTUs, 15 of which belonged to Ascomycota and one to Basidiomycota. Although some authors suggest that basidiomycetes constitute an important part of endophytic communities and low proportions of basidiomycetes may just 


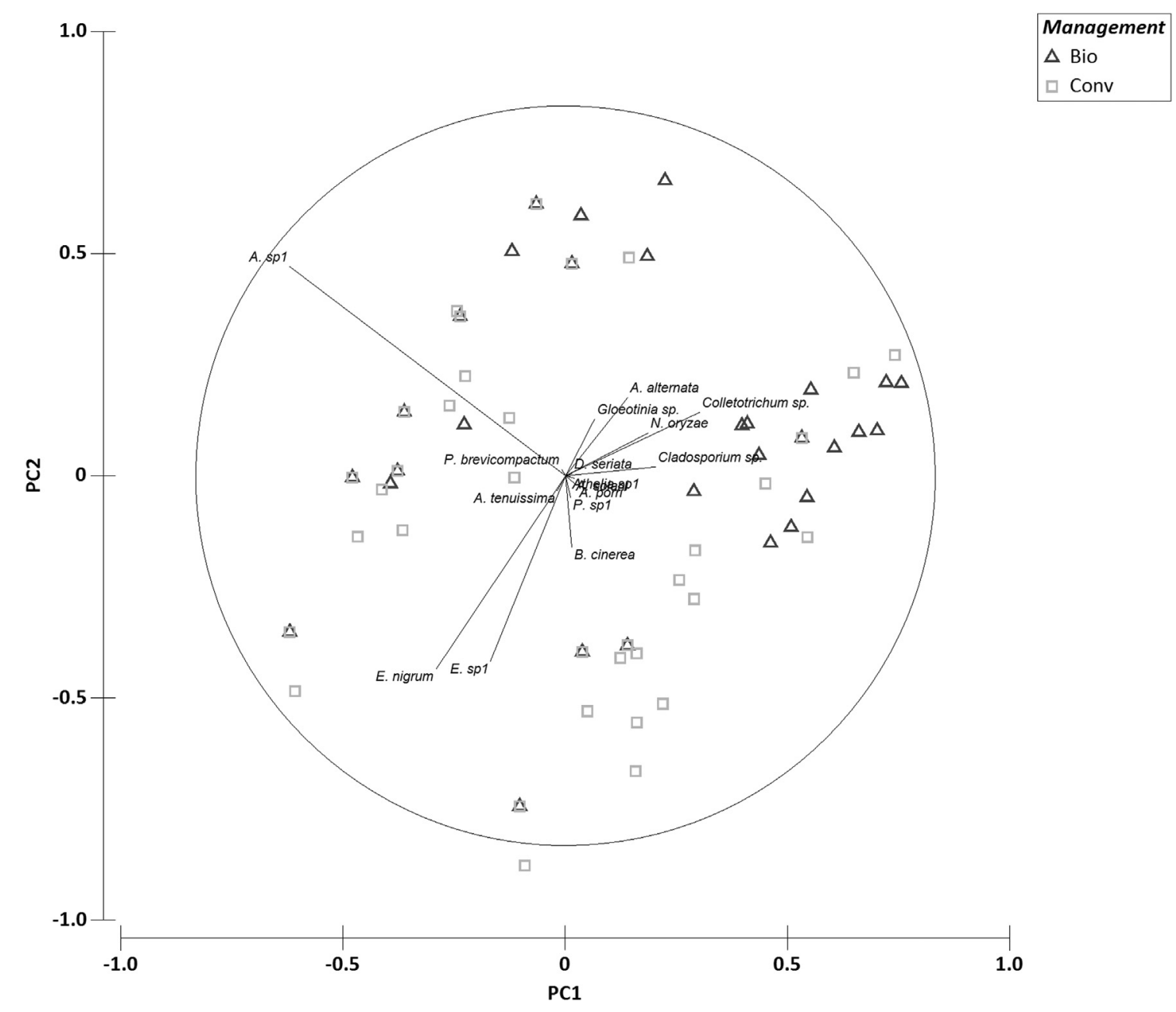

Fig 5 - PCA plot based on presence and absence of fungal OTUs detected as phyllosphere endophytes under two different types of management 'Biological' and 'Conventional' (PC1, 19.8\% and PC2, $17.6 \%$ ).

sometimes reflect sampling bias (Mueller et al. 2004; Pinruan et al. 2010), the predominance of ascomycetes fungi over the basidiomycetes found in this study is consistent with other endophytic studies concerning grapevine (Mostert et al. 2000; Gonzalez \& Tello 2011; Pancher et al. 2012) and other woody plants (Arnold 2007). Within Ascomycota, the Dothideomycetes were the most representative (71 \% of total isolates) and within those, the Pleosporales (66\%), which have shown to be one of the main components of the endophytic mycota of many woody plants including grapevine (Gonzalez \& Tello 2011; Pancher et al. 2012). This is mainly due to Alternaria and Epicoccum species that are the most frequent among fungal endophytes in grapevine, as well as in other plants (Gonzalez \& Tello 2011; Grisan et al. 2011; Pancher et al. 2012; Landum et al. 2016) and have been studied as promising biocontrol agents. Alternaria species are usually the principal fungal component of endophytic communities in phyllospheres, mostly due to their particular life style, producing highly melanised hyphae capable to resist and grow under intense UV radiations. Alternaria species (37 \% of total isolates; $50 \%$ in biological and $50 \%$ in conventional), have shown antagonistic effects against Botrytis cinerea and grapevine downy mildew caused by Plasmopara viticola (Dugan et al. 2002; Musetti et al. 2006). The genus Epicoccum comprises $29 \%$ of total isolates obtained in this study (average $>61 \%$ in conventional mode). This classical endophytic genus has also been reported to possess several antifungal properties against grapevine pathogens such as $P$. viticola or B. cinerea (Fowler et al. 1999). Epicoccum nigrum is being developed commercially due to its capability to produce secondary metabolites with antibiotic activity (Martini et al. 2009). In summary, $66 \%$ of the isolates obtained in this study belonged either to Alternaria or to Epicoccum species, which means that endophytic communities may constitute a source of biocontrol agents useful to control important vine diseases. Although Alternaria sp. was found in similar levels in both modes, Epicoccum species were dominant in the conventional mode.

In general, fungi isolated in this study have been previously reported as grapevine endophytes (Gonzalez \& Tello 2011; Pancher et al. 2012). A low incidence of pathogenic species was detected. With the exception of B. cinerea and Diplodia seriata, no pathogenic species, such as esca, Petri disease and excoriose related fungi were detected, in contrast to other studies that frequently report high isolation rates of $P$. viticola 


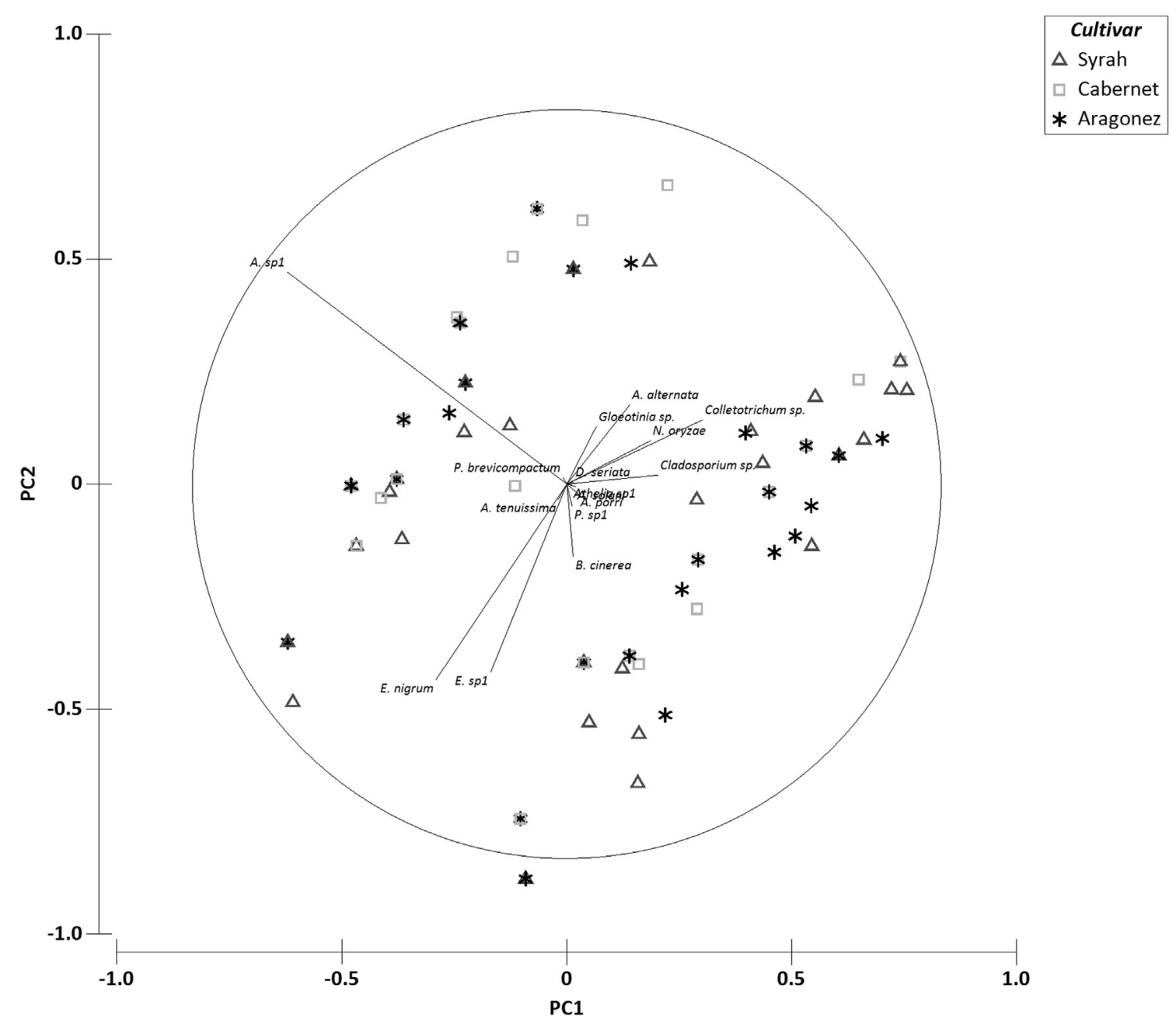

Fig 6 - PCA plot based on presence and absence of fungal OTUs detected as phyllosphere endophytes of three different grape cultivars 'Syrah', 'Aragonez', and 'Cabernet Sauvignon' (PC1, $19.8 \%$ and PC2, $17.6 \%$ ).

(Rodolfi et al. 2006; Gonzalez \& Tello 2011). The common occurrence of $B$. cinerea species as a grapevine endophyte has been frequently reported (Casieri et al. 2009; Gonzalez \& Tello 2011), suggesting that this pathogen is latent, behaving as a plant endophyte, but may become pathogenic under specific physiological or environmental conditions. In addition, Aureobasidium pullulans was not isolated from grapevines in this study. This fungus has shown to be very frequent in grapevine plants (Martini et al. 2009; Gonzalez \& Tello 2011; Grisan et al. 2011; Schmid et al. 2011; Pancher et al. 2012) and its role as antagonist against several pathogens has led to its commercial development to control B. cinerea. Differences found may be due to the cultivars and environmental dissimilarities, which have shown to have a very important impact in the fungi present (Núnez-Trujillo et al. 2012; Pancher et al. 2012).

A higher number of fungi, as well as of OTUs, was observed in grapevines from Syrah cultivar and the lower number of fungi and OTUs was observed in Aragonez. These differences were significant despite the mode of management. Differences in number of fungi were only significant between Syrah and Aragonez. Differences in fungal communities of different grapevine cultivars have been reported (Casieri et al. 2009; Gonzalez \& Tello 2011), but some studies showed no influence in fungal endophyte composition when comparing cultivars (Pancher et al. 2012). Differences in fungal composition of the different cultivars may be related to different plant breeding and selection processes which cultivars have been exposed to; different sugar content, $\mathrm{pH}$ and nutrient composition; differences in phenological stages; or presence and abundance of secondary metabolites produced by the different cultivars. Among the three cultivars used here, some characteristics may partially explain the similarities and differences in fungal endophytic communities. Aragonez is the most different; it has its origin in the Iberian Peninsula and has a higher genetic variability when comparing to Syrah and Cabernet. The latter are among the most used cultivars in the world, they are original from France and very similar in terms of maturation and aroma intensity. Some OTUs were observed only in one of the cultivars, however the low number of isolates $(<4)$ these OTUs present, is not enough to establish a relation with the cultivar, as shown in the PCA (Fig 6), where a homogeneous spread of cultivars is observed. In addition, as for OTUs with more than eight isolates, the 
percentage of isolates in each cultivar never exceeded $60 \%$ and maybe for that reason, again no relation could be established between cultivar and OTU.

When comparing grapevines under the different modes of management, it was observed that the total number of fungi detected was significantly $(p<0.02)$ higher on the conventional than on the biological mode ( $54 \%$ versus $46 \%$ ) which was not expected as conventional treatments have impact on non-target organisms and biological practices are usually linked to higher microbial populations and community diversities (Araújo et al. 2009). This means that products used in biological modes, such as copper, may also have impacts on the microbial communities and should not be disregarded. The higher number of OTUs obtained in the conventional mode than in biological mode did not, however, result in higher diversity indexes, much due to the also higher number of isolates obtained in the conventional mode. Simpson diversity and Shannon diversity indexes show very similar values in both modes (Table 2), with a slight higher diversity value in the biological mode, as observed in previous studies (Pancher et al. 2012). Fungal endophyte composition also showed some differences between both modes. Athelia sp. and D. seriata were only detected in the biological mode and Alternaria porri, Alternaria solani, Penicillium sp., and Penicillium brevicompactum were only detected in the conventional mode. In addition, B. cinerea, Epicoccum sp., and E. nigrum showed to be more frequent in conventional vineyards (87\%, $63 \%$, and $60 \%$, respectively) and Nigrospora oryzae, Cladosporium sp., and Alternaria alternata were more frequent in biological vineyards ( $80 \%, 73 \%$, and $63 \%$, respectively). This shows that composition of phyllosphere fungal communities is different upon the type of culture management. PCA analysis reinforced that fungal community composition showed a separation between the biological and the conventional vineyards (Fig 5). Summing up, plants under the two modes of management revealed differences in terms of total fungal endophyte number, fungal diversity and fungal communities composition. These differences may be related to the use of chemical/organic products that directly affect microorganisms, or to alterations in plant physiology and consequently on plant associated microorganisms. The response of plant associated microbial communities to external products is of great interest for agriculture and further work should focus on the response of plant endophytes to such substances. In addition, some studies have shown that management modes may also interfere on endophytes role, as higher antagonistic effect was observed in endophytes isolated from plants under organic management (Schmid et al. 2011; Pancher et al. 2012). Further studies are needed to test this hypothesis, but this would mean that differences between the two modes of management could be even greater. It would also be interesting to test if antagonistic activities increase due to interactions/synergistic effects of the different fungal species present in the endophytic community. In addition, antagonistic capabilities in the same endophytic fungal species also may vary between plant species, age of the host or plant tissue sampled (Saikkonen et al. 1998). One of the future challenges will be to identify functional differences among endophytic fungi under different conditions.

\section{Acknowledgments}

This work was supported by Inalentejo ALENT-07-0324FEDER-001747, OPERAÇÃO: Gestão Integrada da Proteção do Olival Alentejano. Contributos para o seu desenvolvimento e implementação. Carla Marisa R. Varanda is recipient of a PhD fellowship from Fundação para a Ciência e a Tecnologia (FCT), SFRH/BPD/76194/2011, financed by QREN - POPH Typology4.1-co-financed by MES national funding and the European Social Fund. Mônica D.M. Oliveira received a postdoctoral fellowship from Coordenação de Aperfeiçoamento de Pessoal de Nível Superior (CAPES): CsF/2581/31-2. This work has been supported by FEDER and National funds, through the Programa Operacional Regional do Alentejo (InAlentejo) Operation ALENT-07-0262-FEDER-001871/Laboratório de Biotecnologia Aplicada e Tecnologias Agro-Ambientais.

\section{R E F E R E N C E S}

Anderson MJ, Gorley RN, Clarke KR, 2008. PERMANOVA A+ for PRIMER: guide to software and statistical methods. PRIMER-E, Plymouth, UK.

Araújo A, Leite L, Santos V, Carneiro R, 2009. Soil microbial activity in conventional and organic agricultural systems. Sustainability 1: 268-276.

Araujo W, Marcon J, Maccheroni WJ, Van Elsas J, Van Vuurde J, Azevedo J, 2002. Diversity of endophytic bacterial populations and their interaction with Xylella fastidiosa in citrus plants. Applied and Environmental Microbiology 68: 4906-4914.

Arnold A, 2007. Understanding the diversity of foliar endophytic fungi: progress, challenges, and frontiers. Fungal Biology Reviews 21: 51-66.

Arnold A, Lutzoni F, 2007. Diversity and host range of foliar fungal endophytes: are tropical trees biodiversity hot spots? Ecology 88: 541-549.

Arnold A, Mejía L, Kyllo D, Rojas E, Maynard Z, Robbins N, Herre E, 2003. Fungal endophytes limit pathogen damage in a tropical tree. Proceedings of the National Academy of Sciences of the United States of America 100: 15649-15654.

Bae H, Sicher R, Kim M, Kim S-H, Strem M, Melnick R, Bailey B, 2009. The beneficial endophyte Trichoderma hamatum isolate DIS $219 \mathrm{~b}$ promotes growth and delays the onset of the drought response in Theobroma cacao. Journal of Experimental Botany 60: 3279-3295.

Bulgari D, Casati P, Crepaldi P, Daffonchio D, Quaglino F, Brusetti L, Attilio Bianco P, 2011. Restructuring of endophytic bacterial communities in grapevine yellows-diseased and recovered Vitis vinifera L. plants. Applied and Environmental Microbiology 77: 5018-5022.

Buyer J, Zuberer D, Nichols K, Franzluebbers A, 2011. Soil microbial community function, structure, and glomalin in response to tall fescue endophyte infection. Plant Soil 339: 401-412.

Cabanes F, Bragulat M, Castellá G, 2010. Ochratoxin A producing species in the genus Penicillium. Toxins 2: 1111-1120.

Casieri L, Hofstetter V, Viret O, Gindro K, 2009. Fungal communities living in the wood of different cultivars of young Vitis vinifera plants. Phytopathologia Mediterranea 48: 73-83.

Clarke K, Green R, 1988. Statistical design and analysis for a biological effects study. Marine Ecology Progress Series 46: 213-226.

Clarke KR, Warwick RM, 2001. Changes in Marine Communities: an approach to statistical analysis and interpretation, 2nd edn. Plymouth UK. 
Colwell R, 2013. EstimateS: statistical estimation of species richness and shared species from samples. Version 9 User's Guide and Application Published at: http://purl.oclc.org/estimates

Doyle J, Doyle J, 1987. A rapid DNA isolation procedure for small quantities of fresh leaf tissue. Phytochemical Bulletin 19: $11-15$.

Dugan F, Lupien S, Grove G, 2002. Incidence, aggressiveness and in planta interactions of Botrytis cinerea and other filamentous fungi quiescent in grape berries and dormant buds in Central Washington State. Journal of Phytopathology 150: 375-381.

Ferreira R, Monteiro S, Piçarra-Pereira M, Teixeira A, 2004. Engineering grapevine for increased resistance to fungal pathogens without compromising wine stability. Trends in Biotechnology 22: 168-173.

Fowler, S., Jaspers, M., Walter, M., Steward, A., 1999. Suppression of overwintering Botrytis cinerea inoculum on grape rachii using antagonistic fungi, 52nd New Zealand Plant Protection Conference, pp. 141-147.

Gonzalez V, Tello M, 2011. The endophytic mycota associated with Vitis vinifera in central Spain. Fungal Diversity 47: 29-42.

Grisan S, Martini M, Musetti R, Osler R, 2011. Development of a molecular approach to describe the diversity of fungal endophytes in either phytoplasma infected, recovered or healthy grapevines. Bulletin of Insectology 64: S207-S208.

Hall T, 1999. BioEdit: a user-friendly biological sequence alignment editor and analysis program for Windows 95/98/NT. Nucleic Acids Symposium Series 41: 95-98.

Halleen F, Mostert L, Crous P, 2007. Pathogenicity testing of lesserknown vascular fungi of grapevines. Australasian Plant Pathology 36: $277-285$.

Islam S, Math R, Kim J, Yun M, Cho J, Kim E, Lee Y, Yun H, 2010. Effect of plant age on endophytic bacterial diversity of balloon flower (Platycodon grandiflorum) root and their antimicrobial activities. Current Microbiology 61: 346-356.

Kumaresan V, Suryanarayanan T, 2001. Occurrence and distribution of endophytic fungi in a mangrove community. Mycological Research 105: 1388-1391.

Landum M, Alho J, Rei F, Félix M, Varanda C, 2016. Antagonistic activity of fungi of Olea europaea L. against Colletotrichum acutatum. Microbiological Research 183: 100-108.

Martini M, Musetti R, Grisan S, Polizzotto R, Borselli S, Pavan F, Osler R, 2009. DNA-dependent detection of the grapevine fungal endophytes Aureobasidium pullulans and Epicoccum nigrum. Plant Disease 93: 993-998.

Miller J, Sumarah M, Adams G, 2008. Effect of a rugulos in producing endophyte in Picea glauca on Choristoneura fumiferana. Journal of Chemical Ecology 34: 362-368.

Mostert L, Crous P, Petrini O, 2000. Endophytic fungi associated with shoots and leaves of Vitis vinifera, with specific reference to the "Phomopsis viticola" complex. Sydowia 52: 46-58.

Mueller G, Bills G, Foster M, 2004. Biodiversity of Fungi: inventory and monitoring methods.

Musetti R, Polizzotto R, Vecchione A, Borselli S, Zulini L, D’Ambrosio M, Sanità di Toppi L, Pertot I, 2007. Antifungal activity of diketopiperazines extracted from Alternaria alternata against Plasmopara viticola: an ultrastructural study. Micron 38: 643-650.

Musetti R, Vecchione A, Stringher L, Borselli S, Zulini L, Marzani C, D'Ambrosio M, Sanità di Toppi L, Pertot I, 2006. Inhibition of sporulation and ultrastructural alterations of grapevine downy mildew by the endophytic fungus Alternaria alternata. Phytopathology 96: 689-698.

Núnez-Trujillo G, Cabrera R, Burgos-Reyes R, Da Silva E, Giménez C, Andreea C, Nélida B, 2012. Endophytic fungi from Vitis vinífera L. isolated in Canary Islands and Azores as potential biocontrol agents of Botrytis cinerea Pers.:Fr. Journal of Horticulture, Forestry and Biotechnology 16: 1-6.

Oliveri C, Campisano A, Catara A, Cirvilleri G, 2007. Characterization and fAFLP genotyping of Penicillium strains from postharvest samples and packinghouse environments. Journal of Plant Pathology 89: 29-40.

Oono R, Lefevre E, Simha A, Lutzoni F, 2015. A comparison of the community diversity of foliar fungal endophytes between seedling and adult loblolly pines (Pinus taeda). Fungal Biology 119: 917-928.

Pancher M, Ceol M, Corneo P, Longa C, Yousaf S, Pertot I, Campisano A, 2012. Fungal endophytic communities in grapevines (Vitis vinifera L.) respond to crop management. Applied and Environmental Microbiology 78: 4308-4317.

Petrini O, 1991. Fungal endophytes of tree leaves. In: Andrews JH HSE (ed.), Microbial Ecology of Leaves. Springer-Verlag, New York, pp. 179-197.

Pinruan U, Rungjindamai N, Choeyklin R, Lumyong S, Hyde K, Jones E, 2010. Occurrence and diversity of basidiomycetous endophytes from the oil palm, Elaeis guineensis in Thailand. Fungal Diversity 41: 71.

Polizzotto R, D'Agostin S, Grisan S, Assante G, Pertot I, Andersen B, Musetti R, 2009. Attività di ceppi endofitici di Alternaria spp. nel controllo di Plasmopara viticola. Journal of Plant Pathology 91: 79-80.

Rasche F, Hödl V, Poll C, Kandeler E, Gerzabek M, Van Elsas J, Angela Sessitsch A, 2006. Rhizosphere bacteria affected by transgenic potatoes with antibacterial activities compared with the effects of soil, wild-type potatoes, vegetation stage and pathogen exposure. FEMS Microbiology Ecology 56: 219-235.

Redman R, Dunigan D, Rodriguez R, 2001. Fungal symbiosis from mutualism to parasitism: who controls the outcome, host or invader? New Phytologist 151: 705-716.

Rodolfi M, Legler S, Picco A, 2006. Endofiti fungini di Vitis vinifera in Oltrepò Pavese. Micologia Italiana 35: 25-31.

Rodriguez R, White J, Arnold A, Redman R, 2009. Fungal endophytes: diversity and functional roles. New Phytologist 182: 314-330.

Saikkonen K, Faeth S, Helander M, Sullivan T, 1998. Fungal endophytes: a continuum of interactions with host plants. Annual Review of Ecology, Evolution, and Systematics 29: 319-343.

Sánchez-Torres P, González V, Hinarejos R, Tuset J, 2008. Identification and characterization of fungi associated with esca in vineyards of the Comunidad Valenciana (Spain). Spanish Journal of Agricultural Research 6: 650-660.

Saona N, Albrectsen B, Ericson L, Bazely D, 2010. Environmental stresses mediate endophyte-grass interactions in a boreal archipelago. Journal of Ecology 98: 470-479.

Schmid F, Moser G, Muller H, Berg G, 2011. Functional and structural microbial diversity in organic and conventional viticulture: organic farming benefits natural biocontrol agents. Applied and Environmental Microbiology 77: 2188-2191.

Schmidt H, Ehrmann M, Vogel R, Taniwaki M, Niessen L, 2003. Molecular typing of Aspergillus ochraceus and construction of species specific SCAR-primers based on AFLP. Systematic and Applied Microbiology 26: 138-146.

Schulz B, Boyle C, Draeger S, Rommert A, Krohn K, 2002. Endophytic fungi: a source of novel biologically active secondary metabolites. Mycological Research 106: 996-1004.

Tao G, Liu Z, Hyde K, Lui X, Yu Z, 2008. Whole rDNA analysis reveals novel and endophytic fungi in Bletilla ochracea (Orchidaceae). Fungal Diversity 33: 101-122.

White T, Bruns T, Lee S, Taylor J, 1990. Amplification and direct sequencing of fungal ribosomal RNA genes for phylogenetics. In: Innis MA, Gelfand DH, Sninsky JJ, White TJ (eds), PCR 
Protocols: a guide to methods and applications. Academic Press, Inc, New York, pp. 315-322.

Yousaf S, Andria V, Reichenauer T, Smalla K, Sessitsch A, 2010. Phylogenetic and functional diversity of alkane degrading bacteria associated with Italian ryegrass (Lolium multiflorum) and Birdsfoot trefoil (Lotus corniculatus) in a petroleum oilcontaminated environment. Journal of Hazardous Materials 184: $523-532$. 